\title{
Hypertension in pediatric patients with chronic kidney disease: management challenges
}

This article was published in the following Dove Press journal: International Journal of Nephrology and Renovascular Disease 26 July 2017

Number of times this article has been viewed

\author{
Claire M Gallibois ${ }^{1,2}$ \\ Natasha A Jawa' \\ Damien G Noone' \\ 'Division of Nephrology, The Hospital \\ for Sick Children, Toronto, ON, \\ Canada; ${ }^{2}$ Faculty of Medicine, Royal \\ College of Surgeons in Ireland, Dublin, \\ Ireland
}

\begin{abstract}
In contrast to adults where hypertension is a leading cause of chronic kidney disease, in pediatrics, hypertension is predominantly a sequela, however, an important one that, like in adults, is likely associated with a more rapid decline in kidney function or progression of chronic kidney disease to end stage. There is a significant issue with unrecognized, or masked, hypertension in childhood chronic kidney disease. Recent evidence and, therefore, guidelines now suggest targeting a blood pressure of $<50$ th percentile for age, sex, and height in children with proteinuria and chronic kidney disease. This often cannot be achieved by monotherapy and additional agents need to be added. Blockade of the renin angiotensin aldosterone system represents the mainstay of therapy, although often limited by the side effect of hyperkalemia. The addition of a diuretic, at least in the earlier stages of chronic kidney disease, might help mitigate this problem.
\end{abstract}

Keywords: chronic kidney disease, end-stage renal disease, hypertension, pediatrics, blood pressure, ambulatory blood pressure monitoring, obesity

\section{Introduction}

Chronic kidney disease (CKD) has been suggested to affect 15-74.7 children per million globally; however, no data is available on the rates of CKD in North American children. ${ }^{1}$ Although CKD is relatively rare in children as compared with adults, hypertension (HTN) is highly prevalent. The prevalence of HTN is tenfold higher than in the general pediatric population and known to increase as children progress through the stages of CKD, so that by the time they are on dialysis, $70 \%$ of them will be hypertensive. ${ }^{2,3} \mathrm{CKD}$ and HTN are intrinsically linked. As a primary regulator of blood volume, kidney function is critical to the maintenance of blood pressure (BP). Thus, decreased kidney function may be directly related to increased BP. There are now many studies demonstrating an interaction between CKD and HTN, with HTN likely hastening the progression of CKD toward end-stage renal disease. ${ }^{4-6}$ Addressing HTN may well prevent or abrogate this decline in renal function and has, therefore, become imperative in the management of CKD. What is especially concerning in the pediatric population, however, is that HTN often goes unrecognized - masked - or is inadequately controlled. ${ }^{4,7-9}$ As well as being an associated feature and complication of CKD, and an independent risk factor for CKD progression, HTN also contributes to cardiovascular mortality in these children. ${ }^{4,10-12}$

Due to abnormal vascular regulation in the setting of fluid overload, increased cardiac output and peripheral vascular resistance alone or in combination can lead to HTN 
in CKD. The renin angiotensin aldosterone system (RAAS) activation, due perhaps to intrinsic renal tissue damage with areas of hypoperfusion, leading to angiotensin II-mediated vasoconstriction, salt and water retention, and sympathetic hyperactivity all contribute to HTN in CKD. ${ }^{13}$

Adopting best practices for monitoring and controlling BP is crucial to improve the management of HTN and prevent future end-organ damage. However, diagnosing and managing HTN in pediatric CKD patients remains a challenge. When HTN is diagnosed, antihypertensive drugs, including angiotensin converting enzyme (ACE) inhibitors, might offer renoprotection and delay the progression of $\mathrm{CKD}$, especially in proteinuric states; however, their use in CKD is often limited by side effects such as hyperkalemia. ${ }^{14-16}$ Dietary restriction and monitoring is also a factor in managing HTN, but has proved difficult to control in the pediatric population. ${ }^{17-19}$

\section{Definitions of HTN and CKD in children}

CKD is characterized by a long-term, progressive loss of kidney function, ultimately resulting in end-organ failure. ${ }^{20}$ The International Society of Nephrology Kidney Disease Improving Global Outcomes (KDIGO) guideline has defined pediatric CKD in terms of progression through five stages (Table 1). ${ }^{21,22}$ A wide variety of biomarkers have been used to illustrate the loss of kidney function in CKD. Glomerular filtration rate (GFR), serum creatinine, and cystatin C, are classically used as biomarkers for renal failure. More recently, biomarkers including KIM-1, LFABP, NGAL, and IL-18 have been tested as markers of kidney damage, and may prove useful in the future in defining CKD patients at greater risk for progression. ${ }^{23}$

The North American Chronic Kidney Disease in Children (CKiD) study established that an estimated glomerular filtration rate (eGFR) between 30 and $75 \mathrm{~mL} / \mathrm{min} / 1.73 \mathrm{~m}^{2}$ is a useful guideline for indicating high risk for progression from CKD to end-stage renal disease. ${ }^{22}$

The most widely accepted definition of pediatric HTN was outlined in the Fourth Report on the Diagnosis,

Table I CKD stages in children

\begin{tabular}{lll}
\hline Stage & GFR description & $\begin{array}{l}\text { eGFR } \\
\left(\mathbf{m L} / \mathbf{m i n} / \mathbf{I . 7 3} \mathbf{~ m}^{\mathbf{2}}\right)\end{array}$ \\
\hline I & Normal or elevated & $\geq 90$ \\
II & Mildly decreased & $60-89$ \\
III & Moderately decreased & $30-59$ \\
IV & Severely decreased & $15-29$ \\
V & Kidney failure & $<15$ \\
\hline
\end{tabular}

Abbreviations: CKD, chronic kidney disease; eGFR, estimated glomerular filtration rate; GFR, glomerular filtration rate.
Evaluation, and Treatment of High Blood Pressure in Children and Adolescents. According to these guidelines, HTN in children is defined as an average systolic or diastolic BP equal to or above the 95 th percentile for age, sex, and height, as measured on three or more occasions. Pre-HTN in children is characterized by average readings between the 90th and 95th percentile. ${ }^{24,25}$

\section{Prevalence of HTN in children with CKD}

HTN in children is rare, with a prevalence of 3\%-9\%; however, in children with CKD, the prevalence rises to $50 \%{ }^{4,8,26,27}$ The etiology of HTN in children varies depending on the age of diagnosis. Neonates and infants most commonly have HTN due to renovascular diseases such as renal venous thrombosis or renal artery stenosis, and other renal parenchymal diseases. HTN is probably more prevalent in preterm neonates, with the presence of umbilical lines, postnatal acute kidney injury, patent ductus, intraventricular hemorrhage, and chronic lung disease, all being associated with HTN. ${ }^{28-30}$ In children and adolescents, intrinsic renal parenchymal disease and renovascular disease are the most common causes of HTN. ${ }^{7}$ Secondary HTN is most common earlier in childhood, while adolescents and adults more commonly present with essential HTN. ${ }^{5,31}$ Primary HTN is strongly correlated with overweight in childhood. ${ }^{31}$ Children with CKD most often present with secondary HTN, as BP elevation is a common consequence of renal damage and decreased renal function. ${ }^{5}$

The Kidney Disease Outcome and Quality Initiative found the prevalence of HTN in children with CKD to be $70 \%,{ }^{32}$ and it may even be as high as $80 \%$ in those with stage IV and V CKD. ${ }^{32}$ However, there is a high degree of variability across studies in terms of the rates of HTN in children with $\mathrm{CKD}$. The CKiD cohort, comprising children with CKD across 43 centers in North America, demonstrated that $54 \%$ of children met the criteria for HTN when BP was measured through casual measurements. ${ }^{7,8}$ Of those meeting the criteria for HTN, half were previously undiagnosed or had uncontrolled HTN, while the other half had controlled HTN. ${ }^{7,8}$ A more recent study of the CKiD cohort found that $52 \%$ of patients whose BP was measured by ambulatory blood pressure measurement (ABPM) met the criteria for HTN. ${ }^{27}$ Furthermore, the North American Pediatric Renal Transplant and Collaborative Studies (NAPRTCS) registry determined that $48 \%$ of children met the criteria for HTN at baseline., ${ }^{4,7}$

The prevalence of HTN is further increased in children on dialysis. In the NAPRTCS registry cohort, $76 \%$ of children 
on chronic dialysis had HTN, 57\% of which were cases of uncontrolled HTN requiring further investigation to direct management. ${ }^{33,34}$

\section{Pathophysiology of HTN in CKD}

HTN is rarely a direct cause of CKD in children, in contrast to adult populations; however, it likely contributes to its progression. ${ }^{6,13}$ Increasing BP has been correlated with CKD progression in children. ${ }^{4,5,35} \mathrm{HTN}$ is considered a marker for disease severity in CKD and is a risk factor for accelerated deterioration of kidney function as well as for cardiovascular disease. ${ }^{35,36} \mathrm{HTN}$ increases with decreased eGFR and results in decreased filtrate production. As such, the kidneys are unable to excrete the volume needed to maintain normal BP. ${ }^{6}$

The sympathetic nervous system plays a critical role at the level of the kidneys with the progression and persistence of pediatric HTN. Sympathetic hyperactivity has been noted in CKD and is thought to be mediated by excess free radical formation, reduced nitric oxide (NO) bioavailability, and excessive production of angiotensin II. ${ }^{37,38}$ Free radicals are reactive molecules produced from oxidative stress that induce HTN by increasing cranial sympathetic outflow. ${ }^{38}$ The sympathetic system then acts on afferent arterioles of the kidney causing vasoconstriction, resulting in decreased GFR. ${ }^{38} \mathrm{NO}$ has a tonic inhibitory role in the maintenance of vascular tone. In hypertensive patients, an imbalance exists between $\mathrm{NO}-$ a vasodilator - and other vasoconstrictors. ${ }^{38}$ NO is also known to increase renin, the precursor for the RAAS. The RAAS involves several players: renin is released by juxtaglomerular cells in the kidneys in response to low $\mathrm{BP}$, causing cleavage of angiotensinogen (precursor made in the liver) to angiotensin I. Angiotensin I is, in turn, converted to angiotensin II by ACE in the lungs. Angiotensin II is a vasoconstrictor that accumulates in patients with $C K D$, and results in a variety of downstream effects causing increased BP. Angiotensin II acts on the zona glomerulosa of the adrenal cortex to release aldosterone in order to increase water absorption and sodium uptake from the distal convoluted tubule and the collecting duct; ${ }^{39}$ alters baroreceptor reflexes to higher set points resulting in potentiation of the effects of noradrenaline in the sympathetic nerve terminal; ${ }^{38}$ and stimulates the release of antidiuretic hormone from the pituitary to increase water uptake and associated blood volume. ${ }^{40,41} \mathrm{ACE}$ inhibitors, which block the formation of angiotensin II from angiotensin I, can reduce muscle sympathetic nerve activity in patients with $\mathrm{CKD}{ }^{38}$

HTN, nephron mass, and proteinuria are the three main risk factors for CKD progression. ${ }^{42}$ These factors are intimately linked and have compounding effects on one an other. Loss of nephron mass leads to glomerular hyperfiltration and increased GFR. ${ }^{42}$ Increasing protein in the urine (proteinuria) is caused either by damage to the glomerular capillary wall or by decrease in tubular reabsorption of protein leading to further destruction of the renal tubular cells (as exposure causes interstitial inflammation and subsequent fibrosis). ${ }^{43,44}$ Proteinuria is common in pediatric CKD. Sixty-two percent of the CKiD cohort was found to have significant proteinuria associated with a lower GFR. ${ }^{45}$ Albuminuria has also been demonstrated to be an independent risk factor of pediatric HTN. ${ }^{46}$

Due to abnormal vascular regulation in the setting of fluid overload, increased cardiac output and peripheral vascular resistance alone or in combination can lead to HTN in CKD. RAAS activation, due perhaps to intrinsic renal tissue damage with areas of hypoperfusion, leading to angiotensin II-mediated vasoconstriction, salt and water retention, and sympathetic hyperactivity all contribute to HTN in CKD.

\section{Salt intake, HTN, and CKD}

Animal and human studies have shown that HTN in CKD is associated with decreased salt excretion. ${ }^{47}$ This may be the result of sympathetic nervous system and RAAS activity decreasing salt excretion through the action of angiotensin II. ${ }^{37-39}$ Nephron and tubular damage and associated declining renal mass in CKD also leads to altered or inappropriate sodium chloride handling in the distal nephron and endothelial dysfunction, further impairing salt excretion. ${ }^{47}$ Decreased GFR also ultimately reduces the amount of filtrate at the tubules available for excretion. ${ }^{6}$ Therefore, with a decreased capacity of excretion of sodium, there is an elevated amount of sodium in circulation and this leads to volume expansion. ${ }^{6,38}$ Consequently, salt intake can be viewed as a direct regulator of BP. In children without CKD, each $1000 \mathrm{mg}$ / day sodium intake has been associated with a $1.0 \mathrm{mmHg}$ increase in systolic BP. ${ }^{48}$ As expected, systolic and diastolic $\mathrm{BP}$ reduced significantly after reducing salt intake and there was a greater chance of HTN in children with higher sodium diets (odds ratio=2). ${ }^{48,49}$ In CKD, this reduction in BP was accompanied by a reduction in proteinuria. ${ }^{50}$ As such, reduced salt diets are recommended in children with HTN and CKD. ${ }^{50}$

\section{Obesity and metabolic syndrome: risk factors for CKD in the pediatric population}

Obesity in children continues to be on the rise, with a predicted increase of $40 \%$ in the next decade. ${ }^{51}$ The National Health and Nutrition Examination Survey data showed that 
since 1976-1980, obesity has doubled among preschool children 2-5 years of age and tripled among children and adolescents 6-19 years of age. ${ }^{52,53}$ The most recent National Health and Nutrition Examination Survey data from 2007 to 2008 showed $10 \%$ of infants and toddlers $<2$ years of age had a weight-for-height $\geq 95$ th percentile, and $17 \%$ of children aged 2-19 years had a weight-for-height $\geq 95$ th percentile. ${ }^{54-56}$ In the USA, the prevalence of obesity was $17 \%$ from 2011 to 2014 in the pediatric population. ${ }^{57}$ In Europe, an estimated prevalence of $20 \%$ of children and adolescents are overweight, with one-third of these being considered as obese. ${ }^{58}$ A study conducted in Canada over a 20 -year period found that pediatric nephrology patients had an increased weight compared to the normal population, with consistently higher body mass index (BMI) z-scores (average +0.72). ${ }^{59}$

A high BMI is known to be associated with a low eGFR and an increased prevalence of CKD in the pediatric population. ${ }^{51,60-63}$ Obesity, or increased BMI, can now be considered as a risk factor not just for cardiovascular disease and diabetes, but also for CKD. ${ }^{51,64}$ The increase in CKD in those who are obese is thought to be in part due to increased metabolic demands which, in turn, lead to a compensatory glomerular hyperfiltration injury in the kidney. ${ }^{51,65}$ This is now termed obesity-related glomerulopathy, and it has been speculated that a decrease in the number of functional nephrons might also be implicated in the pathogenesis. ${ }^{65,66}$ Obesity can also lead to RAAS activation along with many other metabolic pathways leading to HTN and the metabolic syndrome. ${ }^{67,68}$

Metabolic syndrome is defined by three metabolic abnormalities such as obesity, elevated BP, low high-density lipoprotein cholesterol, hypertriglyceridemia, and hyperglycemia. ${ }^{68}$ The prevalence of metabolic syndrome in adolescents was $4.5 \%$ from 1994 to 2004, as reported in the US National Health and Nutrition Survey data. ${ }^{68}$ It is estimated from the CKiD study that $13 \%$ of children with CKD had metabolic syndrome. ${ }^{68,69}$ The strong relationship between metabolic syndrome and CKD has become increasingly identified. ${ }^{70-72}$

Although obesity is increasingly prevalent, it is preventable and treatable. Awareness of healthy lifestyles is a key factor in the prevention and treating of obesity in the pediatric population. ${ }^{73}$ Risk modification with body weight reduction, specialized obesity management clinics, antiobesity medications such as orlistat, and surgical options such as gastric banding or bypass remain the therapeutic options. ${ }^{74-76}$ However, it is important to be aware that orlistat may lead to renal impairment. ${ }^{74,77}$ In response to this global epidemic, public health interventions have been made by renal associations such as the International Society of Nephrology. ${ }^{51}$

\section{Uric acid and its effect on HTN and CKD}

The kidneys also play a vital role in purine breakdown, leading to production of uric acid. Declining kidney function inhibits normal clearance of purines, resulting in increased uric acid levels. ${ }^{78}$ Inherited disorders of purine metabolism are the most common cause of hyperuricemia in children. ${ }^{79}$ Hyperuricemia and CKD are tightly linked, as uric acid accumulation is associated with HTN, metabolic syndrome, and microalbuminuria, all of which are also risk factors for CKD progression. ${ }^{80,81}$ Children usually exhibit increased excretion and clearance of uric acid as compared to adults, as evidenced by higher fractional excretion of uric acid. ${ }^{78}$ This decreases and normalizes with age, as a result of decreased tubular reabsorption or increased renal tubular secretion of uric acid. ${ }^{82}$

In children with CKD, there is an association between hyperuricemia, elevated BP, obesity, and renal dysfunction (reduced eGFR and albuminuria). ${ }^{79}$ Seventy percent of those with an eGFR $<60 \mathrm{~mL} / \mathrm{min} / 1.73 \mathrm{~m}^{2}$ had hyperuricemia, compared to $34 \%$ of those with an eGFR $>60 \mathrm{~mL} / \mathrm{min} / 1.73 \mathrm{~m}^{2} .{ }^{79}$ Furthermore, $61 \%$ of those children with HTN had hyperuricemia, in contrast to $43 \%$ of normotensive patients. Hyperuricemia is thought to lead to renal arteriolopathy and HTN through a combination of inhibited endothelial cell proliferation, RAAS activation, vascular smooth muscle cell proliferation, and reduced endothelial NO levels..$^{79,83,84}$

A more recent study from the CKiD group also suggests that hyperuricemia may speed up the progression of $\mathrm{CKD},{ }^{85}$ raising the intriguing question as to whether targeting uric acid might be another renoprotective strategy. In hyperuricemic hypertensive patients, treatment with allopurinol has been shown to slow GFR decline and is associated with a reduced risk of cardiovascular morbidity. ${ }^{86}$ Allopurinol obstructs the production of hepatic urate by acting as a competitive inhibitor of xanthine oxidase. ${ }^{79,86}$ However, allopurinol can also lead to hypersensitivity reactions in children, and should be prescribed with cautious regard for dose. ${ }^{87}$

\section{Effect of HTN on end organs}

HTN can have detrimental effects on end organs, including the kidneys, eyes, and heart. HTN leads to kidney damage and progression of $\mathrm{CKD}$, causes hypertensive retinopathy and resultant visual deficits, ${ }^{88}$ and results in an array of cardiovascular effects, including thickening of the heart muscle. This increase in heart muscle mass causes left ventricular hypertrophy ( $\mathrm{LVH})$ through overexertion of the myocardium, as demanded from the increased BP and afterload. ${ }^{36}$ In the pediatric population, carotid intimal medial thickness is 
correlated with left ventricular mass index (LVMI), indicating the implications of HTN. ${ }^{89}$

LVH may be evident in hypertensive children with CKD. ${ }^{5,9,36,89-92}$ Twenty percent of children in the CKiD cohort with CKD stage II-IV exhibited LVH. ${ }^{9}$ Confirmed HTN and masked HTN were the strongest predictors of LVH in children with CKD. ${ }^{9}$ However, LVH also exists in normotensive children with CKD (up to 49\%), and is positively correlated with LVMI and systolic BP. ${ }^{90}$ Treating BP can cause regression of LVH. ${ }^{93,94}$

Interestingly, pediatric patients with HTN were also found to have decreased performance in a variety of cognitive tests relative to their normotensive counterparts. ${ }^{91,92}$

\section{Monitoring for HTN in children with CKD}

Appropriate BP management is critical for reducing the risk of mortality in CKD. ${ }^{95}$ Diagnosis and monitoring of HTN depends on accurate BP measurements; however, this is complicated in patients with CKD due to disease-induced alterations in diurnal BP rhythms. ${ }^{5,96}$

There are three commonly used ways of monitoring BP: casual BP measurement, self-measured BP, and ABPM. Precise recordings in children are difficult with casual BP measurements, as it is often challenging for the child to sit still for the 5 minutes needed to obtain recordings. With self-measured BP measurements, reliability of data is low. ${ }^{5}$ Therefore, $\mathrm{ABPM}$ is considered to be the best way of defining and determining HTN status in pediatric patients with CKD. ABPM provides diurnal BP rhythm and BP variability by recording measurements over a 24-hour period, and allows for identification of white coat (more common in children vs. adults) and masked HTN. ${ }^{97}$ Identification of masked HTN is critical in children with CKD, as it has been associated with high LVMI and carries a worse prognosis. ${ }^{97,98}$ Twenty-four hour BP measurements are thus an important tool in determining the prognosis of pediatric patients with CKD and planning management.

In children from the CKiD cohort with an eGFR of 30-90 $\mathrm{mL} / \mathrm{min} / 1.73 \mathrm{~m}^{2}, 42 \%$ were normotensive, $4 \%$ had white coat HTN, 35\% had masked HTN, and 14\% had ambulatory HTN. BP load was elevated in 52\%, while mean BP was elevated in only $32 \%$. Creatinine ratio change was also associated with $39 \%$ higher odds of having an abnormal ABPM. ${ }^{27}$ Even in children not previously diagnosed with HTN and not on antihypertensive medications, $57 \%$ were found to have ambulatory HTN. ${ }^{99}$ Collectively, these studies illustrate that masked and undiagnosed HTN is still common in pediatric patients with CKD. In the case of prolonged failure of diagnosis, this HTN could lead to drastic effects on the patients' end organs.

Of note, more recent literature has shown that ABPM can actually have effects on BP, especially diurnal BP. Disturbed sleep and reduced physical activity have both been shown to correlate with nocturnal BP dipping. It has been found that when wearing an ABPM, patients spent less time in bed at night, were more restless during those hours, and had reduced sleep efficiency in general. ${ }^{96}$ During the day, patients were more sedentary while wearing the monitor. In CKD patients, it is common to have a loss of the typical nocturnal decline in BP by $10 \%-20 \%$, as seen in healthy individuals. ${ }^{96}$ This loss is common in patients with CKD, and is associated with $\mathrm{LVH}$ and adverse cardiovascular events. ${ }^{47,96}$ Increased BP variability is related to worse outcome, particularly in patients on dialysis who are subject to marked BP swings. ${ }^{97}$ Therefore, ABPM may influence nondipping in patients with CKD, and physicians should be cautious in determining the prognostic significance of the dipping phenomenon. It is also of note that young females have been found to exhibit significantly less systolic and diastolic BP variability compared to young males, and older children exhibit increased systolic BP variability compared to younger children. ${ }^{99}$

\section{Treatment}

Managing HTN and CKD through interventional treatment is essential for the improved prognosis of pediatric patients. Antihypertensive intervention may be critical in preventing end-organ damage. ${ }^{97}$ There is no definitive guide, but many agencies have put forward guidelines over the past 10 years on the management of HTN in CKD. The American Academy of Pediatrics Fourth Report suggests the target BP for CKD patients is below the 90th percentile. ${ }^{100}$ The European Society of Hypertension more recently defined a target BP reduction to $<75$ th percentile for nonproteinuric $\mathrm{CKD}$ and $<50$ th for proteinuric CKD. ${ }^{101} \mathrm{KDIGO}$ guidelines indicate that antihypertensive therapy should be initiated immediately for children with CKD with a BP over the 90th percentile., ${ }^{702}$ KDIGO now also recommends targeting $\mathrm{BP}<50$ th percentile for children with CKD and proteinuria. ${ }^{102}$ These guidelines are summarized elsewhere. ${ }^{103}$ Treatment regimens depend on the degree of HTN, presence of end-organ damage, and the progression of CKD. ${ }^{5}$ Children with a BP over the 95th percentile without $\mathrm{CKD}$ are recommended to initially begin with lifestyle modifications (i.e., weight control, healthy diet, sodium reduction, and maintained exercise). ${ }^{5,53}$ Dietary adherence is a factor that can be increasingly difficult to control in the pediatric population, but should be a priority to 
the physician. ${ }^{17-19}$ However, the first-line therapy for HTN in children with CKD is RAAS-acting agents. Children receiving RAAS-acting agents had better BP control than those receiving other classes of anti-HTN medication. ${ }^{8}$

The main drug therapy used in children with HTN and CKD consists of ACE inhibitors. Strict BP control and limitation of proteinuria with ACE inhibition can slow the progression of CKD. ${ }^{79}$ Along with angiotensin receptor blockers, the two drugs can improve cardiovascular and kidney outcomes. Combination therapy is suggested to provide a greater antiproteinuric effect than monotherapy. ${ }^{104}$ With pediatric patients, a lower range of dosing per body weight is required in prescribing drug therapy, and monitoring drug side effects throughout usage is essential. Currently, all antihypertensive medication doses are prescribed through the adoption of adult doses. Since the passage and implementation of the Food and Drug Administration Modernisation Act of 1997 and Best Pharmaceutical for Children Act shortly thereafter, USA has generated sufficient data to conclude that most classes of anti-HTN medications may permit approval for pediatric use. ${ }^{5,7}$ The four anti-HTN medications found to be safe and effective in children are Lisinopril (ACE inhibitor), Bisoprolol (beta-1 adrenergic receptor blocker), Amlodipine (long-acting dihydropyridine calcium channel blocker), and Enalapril (ACE inhibitor). Felodipine (dihydropyridine calcium channel blocker) has also shown promising effects. ${ }^{105-110}$

Often a single agent will be insufficient to achieve currently recommended targets for $\mathrm{BP}$ in children with $\mathrm{CKD}$, and multiple agents may be needed. In order to achieve the recommended target of $\mathrm{BP}<50$ th percentile in proteinuric CKD children, as found in the Effect of Strict Blood Pressure Control and ACE Inhibition on Progression of CRF in Pediatric Patients trial, ${ }^{111}$ at least $50 \%$ of children will require additional agents. ${ }^{13}$

The use of diuretics, particularly thiazides, seems prudent in the setting of volume or fluid overload. Adult guidelines, published by the Eighth Joint National Committee, state that a thiazide diuretic, RAAS inhibition (ACE inhibitor or angiotensin receptor blockers), and a longer acting calcium channel blocker are equal as first-line agents for HTN; however, in those with proteinuric CKD, RAAS blockade should be used first. ${ }^{112}$ In the earlier stages of CKD, thiazides may be effective; however, classically, it is taught that their effectiveness decreases once the GFR drops below $60 \mathrm{~mL} / \mathrm{min} / 1.73 \mathrm{~m}^{2}$, and they are ineffectual in CKD stages IV and V, where furosemide may be a better choice. Diuretics likely have both volume and some direct vascular effects. ${ }^{113}$ Initial effect of thiazides is on reducing the extracellular fluid volume overload and cardiac output, possibly due to a decrease in peripheral vascular resistance, the other important contributor to BP. ${ }^{114}$ It should also be noted that the BP-lowering effects of hydrochlorothiazide may take some time, only becoming maximally evident by about 4-6 weeks on the drug, ${ }^{115}$ and furthermore, hydrochlorothiazide exhibits a flat dose-response curve with no significant gains in terms of BP control seen by increasing the dose. ${ }^{114}$ All the relevant pediatric studies of thiazides included a beta-blocker, and none of them could differentiate as to which agent was providing the effect on BP. ${ }^{105,116}$ Thiazide use may result in increased risk of hypokalemia; however, this may prove beneficial, as it may offset the hyperkalemia caused by RAAS blockade.

\section{Conclusion}

CKD and HTN are intimately linked to one another, and act synergistically to cause further decline in renal function. Often masked or under-recognized, HTN presents an important target for treatment and renoprotection. ACE inhibitors and other medications affecting the RAAS are the best drug therapies in pediatric patients with HTN and CKD to date. End-organ damage can be detrimental to the patient and should always be screened for. Monitoring BP is essential for tracking progression of CKD, particularly through the ABPM method in the pediatric HTN population.

\section{Disclosure}

The authors report no conflicts of interest in this work.

\section{References}

1. Warady BA, Chadha V. Chronic kidney disease in children: the global perspective. Pediatr Nephrol (Berlin, Germany). 2007;22(12):1999-2009.

2. Olowu WA. Pre-treatment considerations in childhood hypertension due to chronic kidney disease. World J Nephrol. 2015;4(5):500-510.

3. Tkaczyk M, Stanczyk M, Miklaszewska M, et al. What has changed in the prevalence of hypertension in dialyzed children during the last decade? Ren Fail. 2017;39(1):283-289.

4. Mitsnefes M, Ho PL, McEnery PT. Hypertension and progression of chronic renal insufficiency in children: a report of the North American Pediatric Renal Transplant Cooperative Study (NAPRTCS). J Am Soc Nephrol. 2003;14(10):2618-2622.

5. Swinford RD, Portman RJ. Measurement and treatment of elevated blood pressure in the pediatric patient with chronic kidney disease. Adv Chronic Kidney Dis. 2004;11(2):143-161.

6. Horowitz B, Miskulin D, Zager P. Epidemiology of hypertension in CKD. Adv Chronic Kidney Dis. 2015;22(2):88-95.

7. Halbach S, Flynn J. Treatment of hypertension in children with chronic kidney disease. Curr Hypertension Rep. 2015;17(1):503.

8. Flynn JT, Mitsnefes M, Pierce C, et al. Blood pressure in children with chronic kidney disease: a report from the Chronic Kidney Disease in Children study. Hypertension. 2008;52(4):631-637.

9. Mitsnefes M, Flynn J, Cohn S, et al. Masked hypertension associates with left ventricular hypertrophy in children with CKD. J Am Soc Nephrol. 2010;21(1):137-144. 
10. Chavers BM, Li S, Collins AJ, Herzog CA. Cardiovascular disease in pediatric chronic dialysis patients. Kidney Int. 2002;62(2):648-653.

11. Chavers BM, Herzog CA. The spectrum of cardiovascular disease in children with predialysis chronic kidney disease. Adv Chronic Kidney Dis. 2004;11(3):319-327.

12. Parekh RS, Carroll CE, Wolfe RA, Port FK. Cardiovascular mortality in children and young adults with end-stage kidney disease. J Pediatr. 2002;141(2):191-197.

13. Hadtstein C, Schaefer F. Hypertension in children with chronic kidney disease: pathophysiology and management. Pediatr Nephrol (Berlin, Germany). 2008;23(3):363-371.

14. Persson F, Rossing P. Sequential RAAS blockade: is it worth the risk? Adv Chronic Kidney Dis. 2014;21(2):159-165.

15. Martelli A, Testai L, Breschi MC, Calderone V. Inhibitors of the renal outer medullary potassium channel: a patent review. Expert Opin Ther Pat. 2015;25(9):1035-1051.

16. Te Riet L, van Esch JH, Roks AJ, van den Meiracker AH, Danser AH. Hypertension: renin-angiotensin-aldosterone system alterations. Circ Res. 2015;116(6):960-975.

17. Apostolou A, Karagiozoglou-Lampoudi T. Dietary adherence in children with chronic kidney disease: a review of the evidence. $J$ Ren Care. 2014;40(2):125-130.

18. Rees L, Mak RH. Nutrition and growth in children with chronic kidney disease. Nat Rev Nephrol. 2011;7(11):615-623.

19. Graf L, Candelaria S, Doyle M, Kaskel F. Nutrition assessment and hormonal influences on body composition in children with chronic kidney disease. Adv Chronic Kidney Dis. 2007;14(2):215-223.

20. Johnson CA, Levey AS, Coresh J, Levin A, Lau J, Eknoyan G. Clinical practice guidelines for chronic kidney disease in adults: part II. Glomerular filtration rate, proteinuria, and other markers. Am Fam Physician. 2004;70(6):1091-1097.

21. Kidney Disease: Improving Global Outcomes CWG. KDIGO 2012 Clinical Practice Guideline for the Evaluation and Management of Chronic Kidney Disease. 2013;3(1). Available from: http://www.kdigo. org/clinical_practice_guidelines/pdf/CKD/KDIGO_2012_CKD_ GL.pdf. Accessed May 21, 2017.

22. Goldstein SL, Devarajan P. Acute kidney injury in childhood: should we be worried about progression to CKD? Pediatr Nephrol (Berlin, Germany). 2011;26(4):509-522.

23. Lopez-Giacoman S, Madero M. Biomarkers in chronic kidney disease, from kidney function to kidney damage. World J Nephrol. 2015;4(1):57-73.

24. Update on the 1987 Task Force Report on High Blood Pressure in Children and Adolescents: a working group report from the National High Blood Pressure Education Program. National High Blood Pressure Education Program Working Group on Hypertension Control in Children and Adolescents. Pediatrics. 1996;98(4 Pt 1):649-658.

25. National Institutes of Health. The Fourth Report on the Diagnosis, Evaluation, and Treatment of High Blood Pressure in Children and Adolescents. 2005. Available from: https://www.nhlbi.nih.gov/files/docs/resources/ heart/hbp_ped.pdf. Accessed May 21, 2017.

26. McNiece KL, Poffenbarger TS, Turner JL, Franco KD, Sorof JM, Portman RJ. Prevalence of hypertension and pre-hypertension among adolescents. J Pediatr. 2007;150(6):640-644, 640-644.e1.

27. Samuels J, Ng D, Flynn JT, et al. Ambulatory blood pressure patterns in children with chronic kidney disease. Hypertension. 2012;60(1):43-50.

28. Dionne JM, Abitbol CL, Flynn JT. Hypertension in infancy: diagnosis, management and outcome. Pediatr Nephrol (Berlin, Germany). 2012;27(1):17-32.

29. Flynn JT. Neonatal hypertension: diagnosis and management. Pediatr Nephrol (Berlin, Germany). 2000;14(4):332-341.

30. Flynn JT. Hypertension in the neonatal period. Curr Opin Pediatr. 2012;24(2):197-204.

31. Riley M, Bluhm B. High blood pressure in children and adolescents. Am Fam Physician. 2012;85(7):693-700.

32. Wong H, Mylrea K, Feber J, Drukker A, Filler G. Prevalence of complications in children with chronic kidney disease according to KDOQI. Kidney Int. 2006;70(3):585-590.
33. Agarwal R, Flynn J, Pogue V, Rahman M, Reisin E, Weir MR. Assessment and management of hypertension in patients on dialysis. $J \mathrm{Am}$ Soc Nephrol. 2014;25(8):1630-1646.

34. Mitsnefes M, Stablein D. Hypertension in pediatric patients on long-term dialysis: a report of the North American Pediatric Renal Transplant Cooperative Study (NAPRTCS). Am J Kidney Dis. 2005;45(2):309-315.

35. Klag MJ, Whelton PK, Randall BL, et al. Blood pressure and end-stage renal disease in men. $N$ Engl J Med. 1996;334(1):13-18.

36. Middleton RJ, Parfrey PS, Foley RN. Left ventricular hypertrophy in the renal patient. JAm Soc Nephrol. 2001;12(5):1079-1084.

37. Schiffrin EL, Lipman ML, Mann JF. Chronic kidney disease: effects on the cardiovascular system. Circulation. 2007;116(1):85-97.

38. Thomas P, Dasgupta I. The role of the kidney and the sympathetic nervous system in hypertension. Pediatr Nephrol (Berlin, Germany). 2015;30(4):549-560.

39. Reid IA. Role of nitric oxide in the regulation of renin and vasopressin secretion. Front Neuroendocrinol. 1994;15(4):351-383.

40. Urushihara M, Kagami S. Role of the intrarenal renin-angiotensin system in the progression of renal disease. Pediatr Nephrol (Berlin, Germany). 2016:1-9.

41. Joppich R, Weber P. Effects of ADH on the activity and function of the renin-angiotensin-aldosterone system in infants and in children. Eur J Pediatr. 1976;122(4):303-308.

42. Noone D, Licht C. Chronic kidney disease: a new look at pathogenetic mechanisms and treatment options. Pediatr Nephrol (Berlin, Germany). 2014;29(5):779-792.

43. D’Amico G, Bazzi C. Pathophysiology of proteinuria. Kidney Int. 2003;63(3):809-825.

44. Eddy AA. Progression in chronic kidney disease. Adv Chronic Kidney Dis. 2005;12(4):353-365.

45. Wong CS, Pierce CB, Cole SR, et al. Association of proteinuria with race, cause of chronic kidney disease, and glomerular filtration rate in the chronic kidney disease in children study. Clin J Am Soc Nephrol. 2009;4(4):812-819.

46. Inker LA, Coresh J, Levey AS, Tonelli M, Muntner P. Estimated GFR, albuminuria, and complications of chronic kidney disease. $\mathrm{J} \mathrm{Am} \mathrm{Soc}$ Nephrol. 2011;22(12):2322-2331.

47. Judd E, Calhoun DA. Management of hypertension in CKD: beyond the guidelines. Adv Chronic Kidney Dis. 2015;22(2):116-122.

48. Yang Q, Zhang Z, Kuklina EV, et al. Sodium intake and blood pressure among US children and adolescents. Pediatrics. 2012;130(4): 611-619.

49. Falkner B. Recent clinical and translational advances in pediatric hypertension. Hypertension. 2015;65(5):926-931.

50. McMahon EJ, Campbell KL, Bauer JD, Mudge DW. Altered dietary salt intake for people with chronic kidney disease. Cochrane Database Syst Rev. 2015;(2):CD010070.

51. Kovesdy CP, Furth S, Zoccali C. Obesity and kidney disease: hidden consequences of the epidemic. Rev Med Chil. 2017;145(3):281-291.

52. Sorof J, Daniels S. Obesity hypertension in children: a problem of epidemic proportions. Hypertension. 2002;40(4):441-447.

53. Assadi F. The growing epidemic of hypertension among children and adolescents: a challenging road ahead. Pediatr Cardiol. 2012;33(7):1013-1020.

54. Ogden CL, Carroll MD, Curtin LR, McDowell MA, Tabak CJ, Flegal KM. Prevalence of overweight and obesity in the United States, 1999-2004. JAMA. 2006;295(13):1549-1555.

55. Ogden CL, Carroll MD, Curtin LR, Lamb MM, Flegal KM. Prevalence of high body mass index in US children and adolescents, 2007-2008. JAMA. 2010;303(3):242-249.

56. Gunta SS, Mak RH. Is obesity a risk factor for chronic kidney disease in children? Pediatr Nephrol (Berlin, Germany). 2013;28(10):1949-1956.

57. Ogden CL, Carroll MD, Fryar CD, Flegal KM. Prevalence of obesity among adults and youth: United States, 2011-2014. NCHS Data Brief. 2015;(219):1-8.

58. Cattaneo A, Monasta L, Stamatakis E, et al. Overweight and obesity in infants and pre-school children in the European Union: a review of existing data. Obes Rev. 2010;11(5):389-398. 
59. Filler G, Reimao SM, Kathiravelu A, Grimmer J, Feber J, Drukker A. Pediatric nephrology patients are overweight: 20 years' experience in a single Canadian tertiary pediatric nephrology clinic. Int Urol Nephrol. 2007;39(4):1235-1240.

60. Savino A, Pelliccia P, Chiarelli F, Mohn A. Obesity-related renal injury in childhood. Horm Res Paediatr. 2010;73(5):303-311.

61. Wang Y, Chen X, Klag MJ, Caballero B. Epidemic of childhood obesity: implications for kidney disease. Adv Chronic Kidney Dis. 2006;13(4): 336-351

62. Tullus K. Is there an obesity-related epidemic of CKD starting already in childhood? Nephrol Dial Transplant. 2013;28(Suppl 4): iv114-iv116.

63. Duzova A, Yalcinkaya F, Baskin E, Bakkaloglu A, Soylemezoglu O. Prevalence of hypertension and decreased glomerular filtration rate in obese children: results of a population-based field study. Nephrol Dial Transplant. 2013;28(Suppl 4):iv166-iv171.

64. Foster MC, Hwang SJ, Larson MG, et al. Overweight, obesity, and the development of stage 3 CKD: the Framingham Heart Study. Am J Kidney Dis. 2008;52(1):39-48.

65. Kanasaki K, Kitada M, Kanasaki M, Koya D. The biological consequence of obesity on the kidney. Nephrol Dial Transplant. 2013;28(Suppl 4): iv1-iv7.

66. Tsuboi N, Utsunomiya Y, Hosoya T. Obesity-related glomerulopathy and the nephron complement. Nephrol Dial Transplant. 2013;28(Suppl 4): iv108-iv113.

67. Ruster C, Wolf G. The role of the renin-angiotensin-aldosterone system in obesity-related renal diseases. Semin Nephrol. 2013;33(1):44-53.

68. Litwin M, Niemirska A. Metabolic syndrome in children with chronic kidney disease and after renal transplantation. Pediatr Nephrol (Berlin, Germany). 2014;29(2):203-216.

69. Furth SL, Abraham AG, Jerry-Fluker J, et al. Metabolic abnormalities, cardiovascular disease risk factors, and GFR decline in children with chronic kidney disease. Clin JAm Soc Nephrol. 2011;6(9):2132-2140.

70. Ritz E, Koleganova N, Piecha G. Is there an obesity-metabolic syndrome related glomerulopathy? Curr Opin Nephrol Hypertens. 2011;20(1): 44-49.

71. Tanner RM, Brown TM, Muntner P. Epidemiology of obesity, the metabolic syndrome, and chronic kidney disease. Curr Hypertens Rep. 2012;14(2):152-159.

72. Thomas G, Sehgal AR, Kashyap SR, Srinivas TR, Kirwan JP, Navaneethan SD. Metabolic syndrome and kidney disease: a systematic review and meta-analysis. Clin J Am Soc Nephrol. 2011;6(10):2364-2373.

73. Lobstein T, Jackson-Leach R, Moodie ML, et al. Child and adolescent obesity: part of a bigger picture. Lancet. 2015;385(9986):2510-2520.

74. Rossner S. The obese uremic patient: a newcomer in the nephrology clinic? Nephrol Dial Transplant. 2013;28(Suppl 4):iv117-iv119.

75. Mallamaci F, Ruggenenti P, Perna A, et al. ACE inhibition is renoprotective among obese patients with proteinuria. J Am Soc Nephrol. 2011;22(6):1122-1128.

76. Mallamaci F, Tripepi G. Obesity and CKD progression: hard facts on fat CKD patients. Nephrol Dial Transplant. 2013;28(Suppl 4): iv105-iv108.

77. Coutinho AK, Glancey GR. Orlistat, an under-recognised cause of progressive renal impairment. Nephrol Dial Transplant. 2013;28(Suppl 4): iv172-iv174.

78. Fathallah-Shaykh SA, Cramer MT. Uric acid and the kidney. Pediatr Nephrol (Berlin, Germany). 2014;29(6):999-1008.

79. Noone DG, Marks SD. Hyperuricemia is associated with hypertension, obesity, and albuminuria in children with chronic kidney disease. $J$ Pediatr. 2013;162(1):128-132.

80. Feig DI, Johnson RJ. Hyperuricemia in childhood primary hypertension. Hypertension. 2003;42(3):247-252.

81. Nashar K, Fried LF. Hyperuricemia and the progression of chronic kidney disease: is uric acid a marker or an independent risk factor? Adv Chronic Kidney Dis. 2012;19(6):386-391.

82. Stapleton FB. Renal uric acid clearance in human neonates. J Pediatr. 1983;103(2):290-294.
83. Mazzali M, Kanellis J, Han L, et al. Hyperuricemia induces a primary renal arteriolopathy in rats by a blood pressure-independent mechanism. Am J Physiol Renal Physiol. 2002;282(6):F991-F997.

84. Kohagura K, Kochi M, Miyagi T, et al. An association between uric acid levels and renal arteriolopathy in chronic kidney disease: a biopsybased study. Hypertens Res. 2013;36(1):43-49.

85. Rodenbach KE, Schneider MF, Furth SL, et al. Hyperuricemia and progression of $\mathrm{CKD}$ in children and adolescents: the chronic kidney disease in children (CKiD) cohort study. Am J Kidney Dis. 2015;66(6): 984-992.

86. Feig DI, Soletsky B, Johnson RJ. Effect of allopurinol on blood pressure of adolescents with newly diagnosed essential hypertension: a randomized trial. JAMA. 2008;300(8):924-932.

87. Chao J, Terkeltaub R. A critical reappraisal of allopurinol dosing, safety, and efficacy for hyperuricemia in gout. Curr Rheumatol Rep. 2009;11(2):135-140.

88. Ooi QL, Tow FK, Deva R, et al. The microvasculature in chronic kidney disease. Clin J Am Soc Nephrol. 2011;6(8):1872-1878.

89. Sorof JM, Alexandrov AV, Cardwell G, Portman RJ. Carotid artery intimal-medial thickness and left ventricular hypertrophy in children with elevated blood pressure. Pediatrics. 2003;111(1):61-66.

90. Sinha MD, Tibby SM, Rasmussen P, et al. Blood pressure control and left ventricular mass in children with chronic kidney disease. Clin $J$ Am Soc Nephrol. 2011;6(3):543-551.

91. Lande MB, Kaczorowski JM, Auinger P, Schwartz GJ, Weitzman $M$. Elevated blood pressure and decreased cognitive function among school-age children and adolescents in the United States. $J$ Pediatr. 2003;143(6):720-724.

92. Lande MB, Mendley SR, Matheson MB, et al. Association of blood pressure variability and neurocognition in children with chronic kidney disease. Pediatr Nephrol. 2016;31(11):2137-2144.

93. Ramaswamy P, Lytrivi ID, Paul C, Golden M, Kupferman JC. Regression of left ventricular hypertrophy in children with antihypertensive therapy. Pediatr Nephrol (Berlin, Germany). 2007;22(1):141-143.

94. Kupferman JC, Aronson Friedman L, Cox C, et al. BP control and left ventricular hypertrophy regression in children with CKD. J Am Soc Nephrol. 2014;25(1):167-174.

95. Ku E, Gassman J, Appel LJ, et al. BP control and long-term risk of ESRD and mortality. J Am Soc Nephrol. 2017;28(2):671-677.

96. Agarwal R, Light RP. The effect of measuring ambulatory blood pressure on nighttime sleep and daytime activity - implications for dipping. Clin J Am Soc Nephrol. 2010;5(2):281-285.

97. Palatini P. Ambulatory blood pressure and cardiovascular risk in chronic kidney disease. Curr Hypertens Rep. 2008;10(2):119-126.

98. Thompson AM, Pickering TG. The role of ambulatory blood pressure monitoring in chronic and end-stage renal disease. Kidney Int. 2006;70(6):1000-1007.

99. Barletta GM, Flynn J, Mitsnefes M, et al. Heart rate and blood pressure variability in children with chronic kidney disease: a report from the CKiD study. Pediatr Nephrol (Berlin, Germany). 2014;29(6): 1059-1065.

100. Falkner B, Daniels SR. Summary of the fourth report on the diagnosis, evaluation, and treatment of high blood pressure in children and adolescents. Hypertension. 2004;44(4):387-388.

101. Lurbe E, Cifkova R, Cruickshank JK, et al. Management of high blood pressure in children and adolescents: recommendations of the European Society of Hypertension. J Hypertens. 2009;27(9): $1719-1742$.

102. Wheeler DC, Becker GJ. Summary of KDIGO guideline. What do we really know about management of blood pressure in patients with chronic kidney disease? Kidney Int. 2013;83(3):377-383.

103. Dionne JM. Evidence-based guidelines for the management of hypertension in children with chronic kidney disease. Pediatr Nephrol (Berlin, Germany). 2015;30(11):1919-1927.

104. Berl T. Review: renal protection by inhibition of the renin-angiotensin-aldosterone system. $J$ Renin Angiotensin Aldosterone Syst. 2009;10(1):1-8. 
105. Sorof JM, Cargo P, Graepel J, et al. Beta-blocker/thiazide combination for treatment of hypertensive children: a randomized double-blind, placebocontrolled trial. Pediatr Nephrol (Berlin, Germany). 2002;17(5):345-350.

106. Soffer B, Zhang Z, Miller K, Vogt BA, Shahinfar S. A double-blind, placebo-controlled, dose-response study of the effectiveness and safety of lisinopril for children with hypertension. Am J Hypertens. 2003;16(10):795-800.

107. Rogan JW, Lyszkiewicz DA, Blowey D, Khattak S, Arbus GS, Koren G. A randomized prospective crossover trial of amlodipine in pediatric hypertension. Pediatr Nephrol (Berlin, Germany). 2000;14(12):1083-1087.

108. Wells T, Frame V, Soffer B, et al. A double-blind, placebo-controlled, dose-response study of the effectiveness and safety of enalapril for children with hypertension. J Clin Pharmacol. 2002;42(8):870-880.

109. Trachtman H, Frank R, Mahan JD, et al. Clinical trial of extendedrelease felodipine in pediatric essential hypertension. Pediatr Nephrol (Berlin, Germany). 2003;18(6):548-553.

110. Chaturvedi S, Lipszyc DH, Licht C, Craig JC, Parekh R. Pharmacological interventions for hypertension in children. Cochrane Database Syst Rev. 2014;(2):CD008117.
111. Group ET, Wuhl E, Trivelli A, et al. Strict blood-pressure control and progression of renal failure in children. $N$ Engl J Med. 2009;361(17):1639-1650.

112. James PA, Oparil S, Carter BL, et al. 2014 evidence-based guideline for the management of high blood pressure in adults: report from the panel members appointed to the Eighth Joint National Committee (JNC 8). JAMA. 2014;311(5):507-520.

113. Vasavada N, Agarwal R. Role of excess volume in the pathophysiology of hypertension in chronic kidney disease. Kidney Int. 2003;64(5): 1772-1779.

114. Blowey DL. Diuretics in the treatment of hypertension. Pediatr Nephrol (Berlin, Germany). 2016;31(12):2223-2233.

115. Peterzan MA, Hardy R, Chaturvedi N, Hughes AD. Meta-analysis of dose-response relationships for hydrochlorothiazide, chlorthalidone, and bendroflumethiazide on blood pressure, serum potassium, and urate. Hypertension. 2012;59(6):1104-1109.

116. Bachmann H. Propranolol versus chlorthalidone: a prospective therapeutic trial in children with chronic hypertension. Helv Paediatr Acta. 1984;39(1):55-61.
The International Journal of Nephrology and Renovascular Disease is an international, peer-reviewed open access journal focusing on the pathophysiology of the kidney and vascular supply. Epidemiology, screening, diagnosis, and treatment interventions are covered as well as basic science, biochemical and immunological studies. The manuscript management system is completely online and includes a very quick and fair peer-review system, which is all easy to use. Visit http://www. dovepress.com/testimonials.php to read real quotes from published authors.

Submit your manuscript here: https://www.dovepress.com/international-journal-of-nephrology-and-renovascular-disease-journal 